\title{
Multiparameter Monitoring and Prevention of Fault-Slip Rock Burst
}

\author{
Shan-chao Hu, Yun-liang Tan, Jian-guo Ning, Wei-Yao Guo, and Xue-sheng Liu \\ State Key Laboratory of Mining Disaster Prevention and Control Co-Founded by Shandong Province and the Ministry of \\ Science and Technology, Shandong University of Science and Technology, Qingdao 266590, China
}

Correspondence should be addressed to Yun-liang Tan; yunliangtan@163.com, Jian-guo Ning; ningjianguo@sohu.com, and Wei-Yao Guo; 363216782@qq.com

Received 16 November 2016; Accepted 23 March 2017; Published 3 April 2017

Academic Editor: Ivo Caliò

Copyright (C) 2017 Shan-chao Hu et al. This is an open access article distributed under the Creative Commons Attribution License, which permits unrestricted use, distribution, and reproduction in any medium, provided the original work is properly cited.

\begin{abstract}
Fault-slip rock burst is one type of the tectonic rock burst during mining. A detailed understanding of the precursory information of fault-slip rock burst and implementation of monitoring and early warning systems, as well as pressure relief measures, are essential to safety production in deep mines. This paper first establishes a mechanical model of stick-slip instability in fault-slip rock bursts and then reveals the failure characteristics of the instability. Then, change rule of mining-induced stress and microseismic signals before the occurrence of fault-slip rock burst are proposed, and multiparameter integrated early warning methods including mininginduced stress and energy are established. Finally, pressure relief methods targeting large-diameter boreholes and coal seam infusion are presented in accordance with the occurrence mechanism of fault-slip rock burst. The research results have been successfully applied in working faces 2310 of the Suncun Coal Mine, and the safety of the mine has been enhanced. These research results improve the theory of fault-slip rock burst mechanisms and provide the basis for prediction and forecasting, as well as pressure relief, of fault-slip rock bursts.
\end{abstract}

\section{Introduction}

With the increase of coal mining depth, the frequency and intensity of coal and rock dynamic failure phenomena increase dramatically $[1,2]$. As one main type of tectonic rock burst, fault-slip rock burst often takes place near faultslip surfaces. Fault-slip bursts induced by mining activities can inflict severe damage to nearby mine developments, and several fault-slip-related seismic events that have caused damage in underground mines have been reported over the past several decades [3-5]. Therefore, there is practical significance in understanding the precursory information of fault-slip rock burst and implementing monitor and early warning systems, as well as pressure relief, to maintain safety production in deep mines [6-10].

Fault-slip rock burst is induced by the sudden relative movement between the hanging wall and footwall of a fault during mining activities [11, 12]. To date, several methods have been used to study the mechanism and controlling factors of fault-slip rock burst in underground works. In theoretical analysis of mechanical mechanisms of stickslip failure, Pan et al. [13] and $\mathrm{Li}$ et al. [14] established mathematical models. In laboratory tests and numerical simulations, Qi et al. [15], Wang et al. [16], and Gong et al. [17] verified the failure characteristics of nonsteady slip or stick-slip in coal and rock structures and analyzed the failure angle of the rock mass when rock burst occurred. Sainoki and Mitri reproduced the processes and mechanisms of mininginduced fault slip [18-21].

Compared with other research methods, field measurements are more useful in practice. Many researchers have made contributions to the monitoring and prediction of rock bursts and proposed many kinds of monitoring methods $[3,7,8,22-27]$. Williams et al. [3] used the macroseismic monitoring system to study the fault-slip source mechanism. Tan et al. [22], Jiang et al. [23], Li et al. [24], and Lü et al. [25] studied the patterns and early warning methods of microseismic activity of fault-slip rock burst, respectively. Jiang et al. [26] acquired electromagnetic information before and after the occurrence of fault-slip rock burst in field tests. 
Some researchers have proposed using an anchor cable to monitor fault movement [27]. It is thus evident that the current achievements in fault-slip rock burst monitoring have mainly focused on seismic monitoring, while stress monitoring is seldom involved. The reason is that it is difficult to monitor stress in noncoal mines due to the hard rock. However, mining-induced stress measurement is usually used to predict the rock burst in coal mine as the stress in the coal can be easily measured. The mining-induced stress is the stress variation relative to the in situ stress which can be measured using the coal stress meter.

At present, many of the methods used to monitor rock burst are aimed at variations in a single physical quantity, such as mining-induced stress, acoustic emissions, and electromagnetic radiation (EMR). According to the authors' survey in person, the single EMR method was used in Muchengjian Mine in Beijing City, while the single mining-induced stress measurement was adopted in Zhaolou Mine in Shandong Province. However, several factors lead to coal bursts, and therefore it is difficult to acquire adequate monitoring results if only one physical quantity is monitored. In addition, the occurrence mechanisms and features of different types of rock burst are different, and so are the technical principles, monitoring objects, and monitoring ranges of various monitoring methods [28]. Therefore, a single default choice of monitoring method is unable to ensure the accurate recognition of the rock burst danger underlying a working face. Statistically, during the past decade's exploitation of coal seams in Muchengjian Mine, there were nearly 30 rock burst events. In Suncun Mine, a rock burst with a magnitude of 2.3 occurred, and some miners were injured.

To address this problem, this paper first studies the occurrence mechanism and precursory information of faultslip rock burst and then puts forward multiparameter monitoring and early warning methods adapted to the fault-slip rock burst mechanisms, as well as technical solutions for alleviating rock burst hazard; finally, it verifies the proposed principles and methods via practical case studies.

\section{Model Description}

Based on laboratory experiments, fault-slip rock burst is thought to be caused by instability sliding of coal body $[15,16]$. This paper, on the basis of previous studies [13, 14], considers features of fault-slip instability and sets up a mathematical model reflecting stick-slip fault instability to study the occurrence mechanism of fault-slip rock burst. When the working face moves from hanging wall of the fault to fault surface, the footwall remains stable, and the hanging wall will undergo displacement relative to the footwall. A mathematical model can be set up, as shown in Figure 1, by taking the fault surface as the fixed surface and simplifying the hanging wall to be the slider. Assume that the stiffness of the surrounding rock of hanging wall is $k_{1}$, the stiffness of surrounding rock of the footwall is $k_{2}$, the force acting on the footwall is $W$, and the hanging wall deforms with a velocity $v$ relative to the footwall; the coefficient of static friction and coefficient of dynamic friction of the fault surface are $\mu$ and

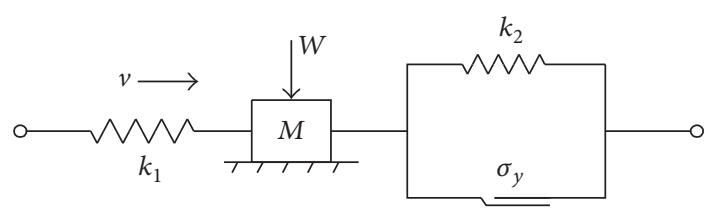

FIGURE 1: Mode of stick-slip fault instability in fault-slip rock burst.

$\mu^{\prime}$, respectively. In the model, the yield stress of the plastic component is $\sigma_{y}$, and the system will be broken when the system stress $\sigma$ exceeds $\sigma_{y}$. The failure state of the system will be analyzed under the conditions of $\sigma\left\langle\sigma_{y}\right.$ and $\sigma>\sigma_{y}$ in detail.

(1) For $\sigma<\sigma_{y}$. The system is in a state of static balance before the slider moves. Assume that the required spring deformation that can overcome the static friction to make the hanging wall and the footwall slide suddenly is $\xi_{0}$; then $\mu W=k_{1} \xi_{0}$.

When the stress exerted by the spring is larger than the static friction, the slider starts to move, and as $\sigma<\sigma_{y}$, the plastic component is not damaged. Assume that the time at which the slider moves suddenly is $t=0$, and take it as the initiation of spring deformation $\xi=v t$, making the displacement of the spring $s$ and its speed $v_{M}$; then the strength exerted by the surrounding rock of the hanging wall is $k_{1}\left(\xi_{0}+\xi-s\right)$. At this time, the system is unbalanced, so the motion equation for the slider can be inferred as [13]:

$$
m a=m \frac{d s^{2}}{d^{2} t}=k_{1}\left(\xi_{0}+\xi-s\right)-\mu^{\prime} W,
$$

in which $a$ denotes acceleration. Make $n^{2}=k_{1} / m$, solve the differential equation using the initial conditions $t=0, s=0$, and $v_{M}=0$, and then the expressions for the displacement $s$ and velocity $v_{M}$ of slider can be presented respectively as follows [14]:

$$
\begin{aligned}
s= & -\frac{\left(\mu-\mu^{\prime}\right) W}{m n^{2}} \cos n t-\frac{v}{n} \sin n t+v t \\
& +\frac{\left(\mu-\mu^{\prime}\right) W}{m n^{2}}, \\
v_{M}= & v(1-\cos n t)+\frac{\left(\mu-\mu^{\prime}\right) W}{m n} \sin n t .
\end{aligned}
$$

When $v_{M}=0$, the time it takes to make the slider be static is

$$
\begin{aligned}
& t_{1}=0, \\
& t_{2}=\frac{1}{n}\left[\pi-\arctan \frac{\left(\mu-\mu^{\prime}\right) W}{m n v}\right] .
\end{aligned}
$$

At $t_{2}$, the displacement of the slider is

$$
s_{2}=v t_{2}+2 \frac{\left(\mu-\mu^{\prime}\right) W}{m n^{2}} .
$$




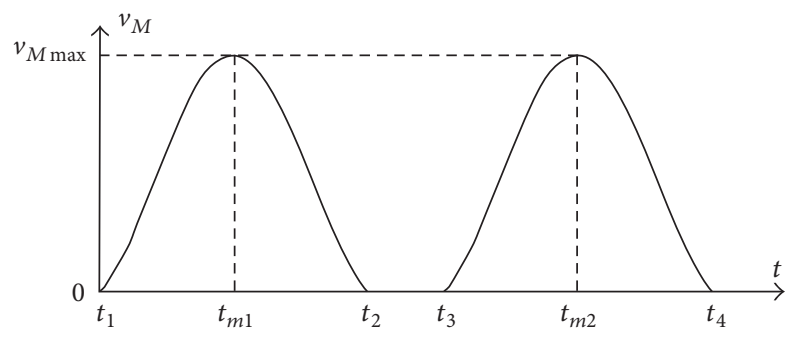

FIGURE 2: Change curve of velocity with time for the slider.

Based on the displacement $s_{2}$ found from (4), the system stress can be inferred to be $\sigma_{1}=k_{1}\left(\xi_{0}+v t_{2}-s_{2}\right)$. When $\sigma_{1}<\sigma_{y}$, the plastic components are undamaged. The spring continuously exerts stress on the slider, making $\sigma_{1}$ increase gradually. After $\sigma_{1}$ exceeds the maximum static friction force, the slider moves again and gradually stops. Based on this, the change in velocity with time of the slider can be acquired as shown in Figure 2.

(2) For $\sigma>\sigma_{y}$. As the slider undergoes stick-slip motion, the force on the system increases gradually and finally reaches $k_{1} s>\sigma_{y}$, where the stress on plastic components exceeds the critical stress, causing failure of the fault and making the whole system unbalanced; when the value of $\sigma_{y}$ is low, the force on the system is small, and the energy released is less damaging; however, when the value of $\sigma_{y}$ is high, the system will accumulate high stress and elastic energy, and then massive energy will be suddenly released, causing damage and leading to rock burst.

Based on this theoretical analysis, it can be concluded that the fault-slip surface shows the characteristics of stick-slip, with intermittent and sudden failure before the fault-slip rock burst takes place. The fault-slip rock burst is mainly induced by the concentration of stress and energy storage, which can provide a theoretical basis for monitoring and prevention of fault-slip rock burst.

\section{Monitoring Approaches}

The monitoring and prevention of different types of rock burst should be based on the precursor information of the corresponding rock burst, and then the appropriate multiparameter method should be used to predict and eliminate the rock burst. According to the features of fault-slip rock burst obtained in this study, fault-slip rock burst monitoring should focus on the change in mining-induced stress and variation in energy. In view of these considerations, this paper constructs a multiparameter monitoring and early warning system based on stress and energy measurements.

3.1. Stress Monitoring. In the mining space, mining activity will change the stress field and energy, and the problem of rock burst can be assumed to be equivalent to the problem of mining-induced stress. Therefore, it is reasonable to judge rock burst by the temporal and spatial evolution of the mining-induced stress, and the monitoring method is more

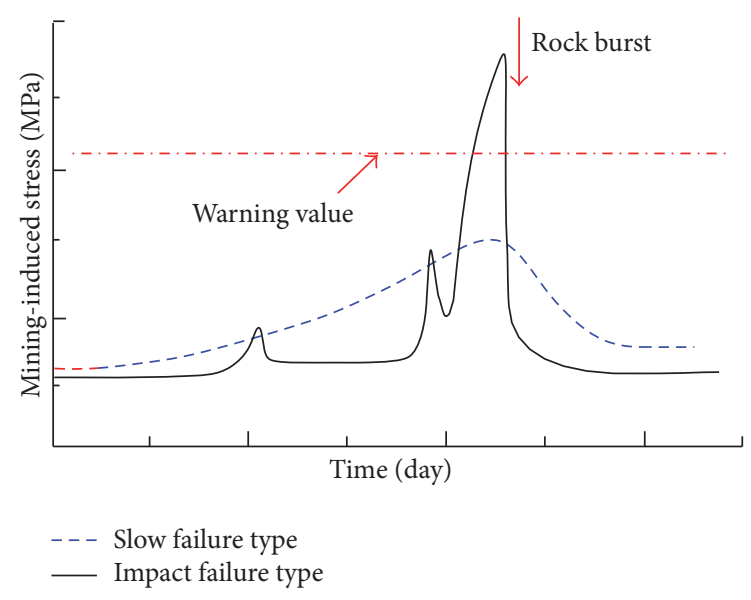

FIGURE 3: Change curve for mining-induced stress of fault-slip rock burst.

intuitive. However, rock burst is generally judged by the realtime mining-induced stress of coal and its changing trends, because it is very difficult to directly obtain the absolute stress of coal.

When the working face advances towards the fault-slip surface, the abutment pressure of working face will be added to the fault tectonic stress, making the stress on the coal and rock mass continuously increase to accrue stress concentration. As the working face gets close to the fault, if the mininginduced stress in coal increases slowly but still smaller than the early warning value or the mining-induced stress exceeds the early warning value but can be decreased by effective methods (which will be discussed in the Section 4.4), the rock burst will not occur, as the mining-induced stress shows little change (slow failure type in Figure 3). If the superimposed stress continuously increases and exceeds the early warning value, then massive elastic energy will accumulate in the coal in a short time. If no pressure relief method is taken, rock burst is highly likely to occur. After the rock burst takes place, the mining-induced stress in coal will experience a sudden drop and falls to a low value (impact failure type in Figure 3).

It should also be noted that rock burst hazard level and the delimited hazardous area of the rock burst cannot be measured by measuring mining-induced stress at one point. It requires continuous real-time monitoring on many points influenced by the mining-induced stress to exactly evaluate the hazardous area and hazard level of rock burst.

3.2. Microseismic Monitoring. Microseismic monitoring technology counts the intensity, frequency, and location of microseismic activity by searching and locating low-frequency $(0-150 \mathrm{~Hz})$ rupture events with high energy $\left(>10^{2} \mathrm{~J}\right)$, as well as calculating the energy released. Therefore, the hazardous area and hazard level of the rock burst can be judged by analyzing the dynamic performance, distribution, and energy dissipation of microseismic activity.

As the working face gets close to the fault, the rock mass begins to fracture near the fault-slip surface, and the energy and frequency of microseismic events increase. Based on the 


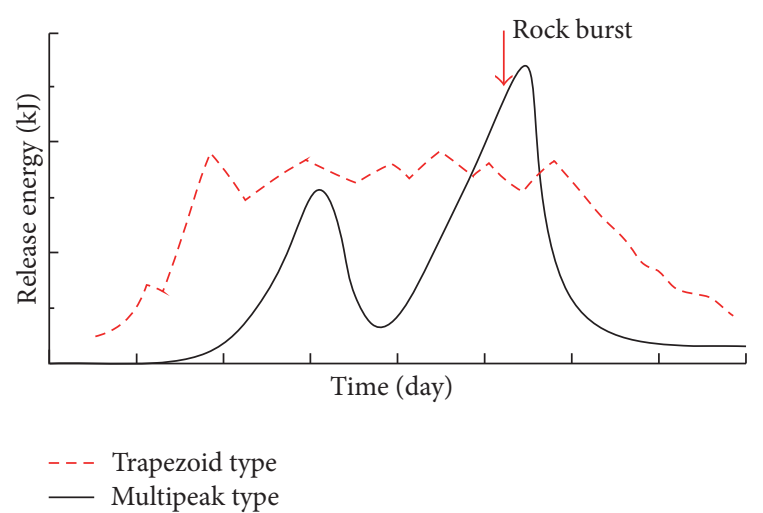

FIGURE 4: Variation in the microseismic signal during a fault-type rock burst.

mechanical model established above, it can be noted that the microseismic signals near the fault have two types [29], which are shown in Figure 4. If the vibration interval of microseismic events is more uniform and the released energy can maintain a relative high level and then decrease slowly, which means the accumulated elastic strain energy near the fault-slip surface can be released, then the rock burst hazard will be low (trapezoid type in Figure 4). If the energy released by microseismic events appears as multiple peaks and the energy released between two adjacent peaks is small, which means the accumulated stress and elastic strain energy near the fault-slip surface are large, then the rock burst hazard will be high (multipeak type in Figure 4).

\section{Case Study}

4.1. Geological Conditions. To ensure the effectiveness of the monitoring and early warning system for rock burst hazard established in this paper, a monitoring system was arranged in working face 2309 in Suncun Coal Mine. The coal seam mined in working face 2309 is the number 4 layer coal, with an average mining depth of $1300 \mathrm{~m}$, average thickness of $3.86 \mathrm{~m}$, and mean angle of $25.5^{\circ}$. The immediate roof is siltstone, with an average thickness of $3.78 \mathrm{~m}$, while the main roof is medium sandstone, with an average thickness of $9.32 \mathrm{~m}$; the immediate floor is mudstone, with an average thickness of $1.65 \mathrm{~m}$. In the middle of the working face, there is a normal fault, CF21, obliquely crossing the working face, with a fault throw of $8.0 \mathrm{~m}$, an inclination of $55^{\circ}$, and a distance $355 \mathrm{~m}$ away from the open-off cut, as shown in Figure 5.

According to measurements conducted by the rock mechanics laboratory of the Beijing Mining Research Institute of China Coal Research Institute, the uniaxial compression strength of the number 4 layer coal is $18.61 \mathrm{MPa}$, with high brittleness and elasticity as well as strong burst hazard. The uniaxial compression strength of the siltstone in the immediate roof is $64.83 \mathrm{MPa}$, while that of the medium sandstone in the main roof is $84.83 \mathrm{MPa}$, and the roof rock of the working face possesses very high burst hazard. In addition, the advancing abutment pressure and the fault tectonic stress are superimposed because of the fault in front of the working face, and the elastic energy accumulated in the coal near the fault, which could easily result in rock burst.

4.2. Monitoring Schemes. To determine the dynamic behavior of the working face when approaching the fault and control its development, Suncun Coal Mine adopted a stress monitoring and microseismic monitoring system to conduct real-time monitoring in the near field of the mining face and for global scope, respectively.

The on-line stress monitoring system (KJ743, Uroica Mining Safety Engineering Co., Ltd.) and microseismic monitoring system (KJ551, Beijing Anke Technology Co., Ltd.) are shown in Figure 6, and the layout of monitoring stations is shown in Figure 5.

The on-line stress monitoring system was arranged in the head entry and tail entry of working face 2309 , and the monitoring stations were laid out $30 \mathrm{~m}$ away from the working face. The installation depths for the stress meters at each monitoring point were $8 \mathrm{~m}$ and $14 \mathrm{~m}$, with $25 \mathrm{~m}$ between sets. Supplementary arrangements $200 \mathrm{~m}$ in front of the working face should be maintained as the working face advances to the stress drill.

For the microseismic monitoring system, four demodulators were arranged in the head entry and tail entry of working face 2309 , respectively, with a spacing of $50 \mathrm{~m}$, allocated to the two sides of fault CF21. The demodulator was installed in the roof at a depth of $18 \mathrm{~m}$ by a drill hole with a diameter of $58 \mathrm{~mm}$. The stress and microseismic monitoring systems automatically recorded the data and then transferred it to the surface by telecommunication cable.

4.3. Monitoring Results. The monitoring results are shown in Figure 7, and the selected stress data are from the monitoring drill hole $20 \mathrm{~m}$ away from the fault. In Figure $7(\mathrm{a})$, the value of mining-induced stress remained fixed before July 28 , where the mining-induced stress of the deep hole was 8.4 MPa, while that of the shallow hole was 7.3 MPa. As the working face advanced to the monitoring drill hole at a distance of about $37 \mathrm{~m}$, mining-induced stress in the coal body increased significantly, and the data fell into the range where the concentration of stress imposes evident influence, with the mining-induced stress of both deep and shallow holes reaching 10.3 MPa. After this, the stress of the deep hole declines and that of the shallow hole surges to its peak of $12.8 \mathrm{MPa}$, whereupon it suddenly plunges (the stress meter in shallow hole is destroyed at this moment), showing that the slip of the fault has caused the destruction of the shallow coal body, and the peak stress moves towards the deep coal body. As the working face advances to the monitoring drill hole at a distance of $21 \mathrm{~m}$, the stress of the deep hole rises rapidly, reaches its peak of $14.6 \mathrm{MPa}$, and then abruptly drops to 0 (the stress meter in the deep hole is destroyed at this moment). In Figure 7(b), the microseismic energy and frequency remain at low levels, after which the microseismic energy goes through a recurring process of increasing and decreasing while its frequency trends grow higher on the whole. After reaching the maximum of $1.61 \times 10^{5} \mathrm{~J}$ at 7.3 , the microseismic energy gradually declines to its minimum of 


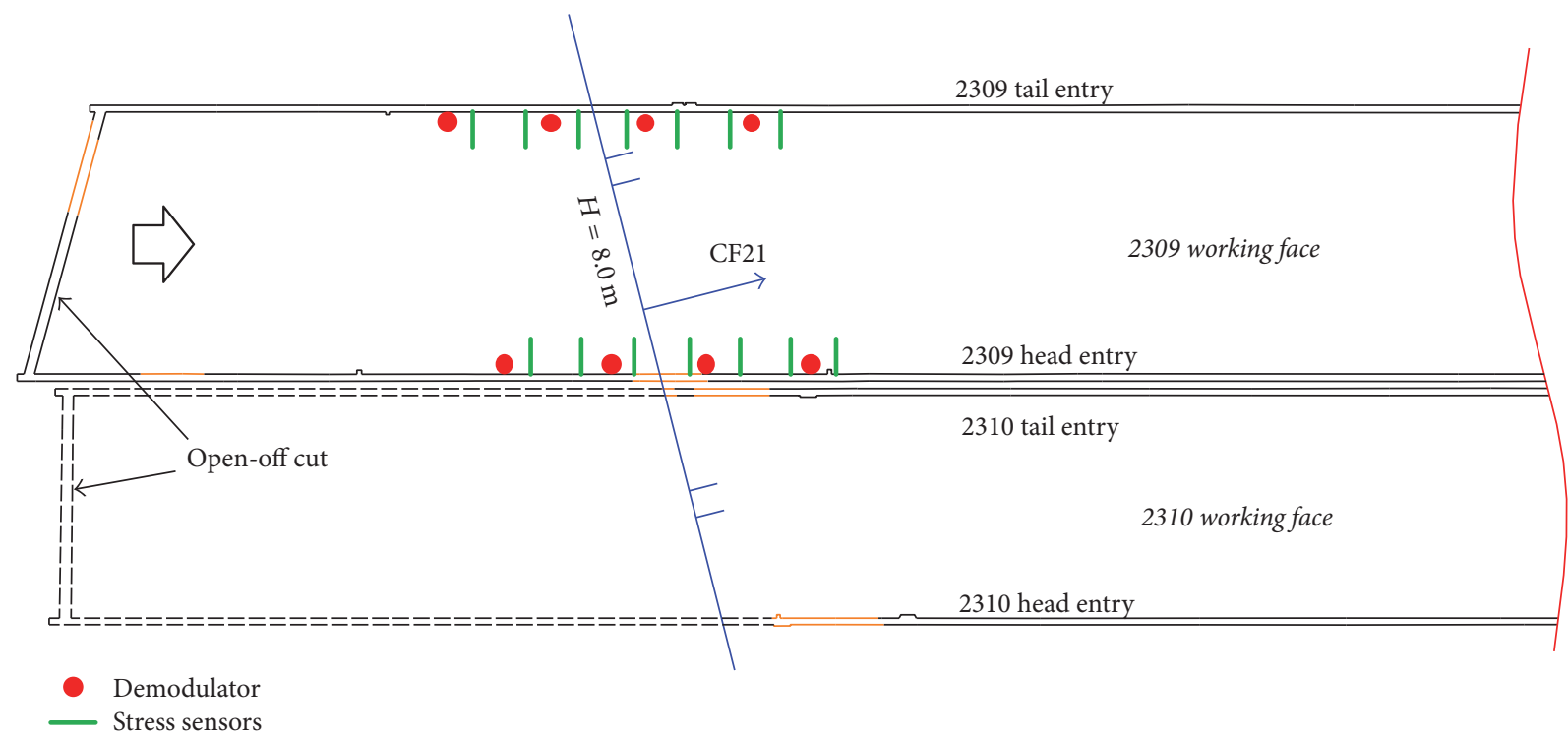

FIGURE 5: Geologic aspects of the working face and layout of monitoring stations.

$4.6 \times 10^{4} \mathrm{~J}$, then gradually increases and reaches its peak of $2.94 \times 10^{5} \mathrm{~J}$, and then slumps to its minimum of $1.2 \times 10^{4} \mathrm{~J}$.

On July 9, 2013, a rock burst with a magnitude of 1.9 occurred at working face 2309 of the Suncun Coal Mine. The energy of microseismic events reached $2.94 \times 10^{5} \mathrm{~J}$. The two sides of the entries became evidently closer, and several props were snapped, as seen from Figure 8. From a comprehensive analysis of mining-induced stress and the microseismic results, the coal body stress was found to have gone through a recurrent process of increasing and decreasing before the rock burst occurred. The microseismic energy trend also increased, decreased, and then increased again while the frequency of vibration generally rose. Finally, the rock burst occurred due to disturbance from the mining activity when the coal body reached its ultimate stress state. Thus, as mining-induced stress and microseismic energy in the coal body showed a recurrent pattern of rising and falling values, rock burst mitigation should have been undertaken before the monitoring parameters reached their second peak.

4.4. Pressure Relief of Rock Bursts. To ensure safety as subsequent working faces pass through CF21 fault, measures should be taken to avoid burst hazards in the coal-rock body around the fault. The root cause of fault-slip rock burst is an increase in the shear stress or decrease in the shear strength on the fault-slip surface induced by mining activities, triggering the sudden relative slide of the fault's two sides. Setting up protective coal pillars would fundamentally eliminate hazards caused by rock bursts of this kind; if mining across the fault is inevitable, large-diameter boreholes should be bored for pressure relief, and coal seam water infusion should be conducted to release the deformation energy accumulated around the fault structure band in advance.

In this case, taking into consideration the geological conditions of working face 2310 in the Suncun Coal Mine, the method of boring large-diameter holes for pressure relief was adopted. As the working face advanced to the fault at a distance of about $80 \mathrm{~m}$, destressing boreholes in the tail entry were set up; as the working face continued to advance, destressing boreholes were set up in the head entry. The distance between the borehole and the coal seam floor was $1.8 \mathrm{~m}$. The boreholes in the entries were set up perpendicular to the gateway sidewall along the direction of the dip angle of the coal seam, and the boreholes in the working faces were set up perpendicular to the coal wall along the direction of the dip angle of coal seam, with the hole diameter of $118 \mathrm{~mm}$, hole depth of $25 \mathrm{~m}$, and spacing of $3 \mathrm{~m}$, as seen from Figure 9.

The contrasting results from microseismic monitoring data between working face 2309, which did not have any pressure relief measures, and that of working face 2310 after pressure relief are shown in Figure 10. According to Figure 10, the seismic energy after pressure relief increased first before it decreased, without showing the repetitive updown processes. The maximum seismic energy after pressure relief was $41 \mathrm{~kJ}$, that is, $57.1 \%$ of the seismic energy peak value of working face 2309 , which means the pressure relief measures applied to the working face are reasonable and effective, because the rock burst hazard of the working face is obviously relieved.

\section{Conclusions}

To secure the safety mining of the working faces that are in danger of rock burst while getting through a fault, it is necessary to study the precursory information and failure features of fault-slip rock bursts and implement relevant methods of early warning monitoring and pressure relief.

(1) When a mining face gradually advances to a fault, the advancing abutment pressure of the working face will be superposed onto fault tectonic stress, making the fault-slip 


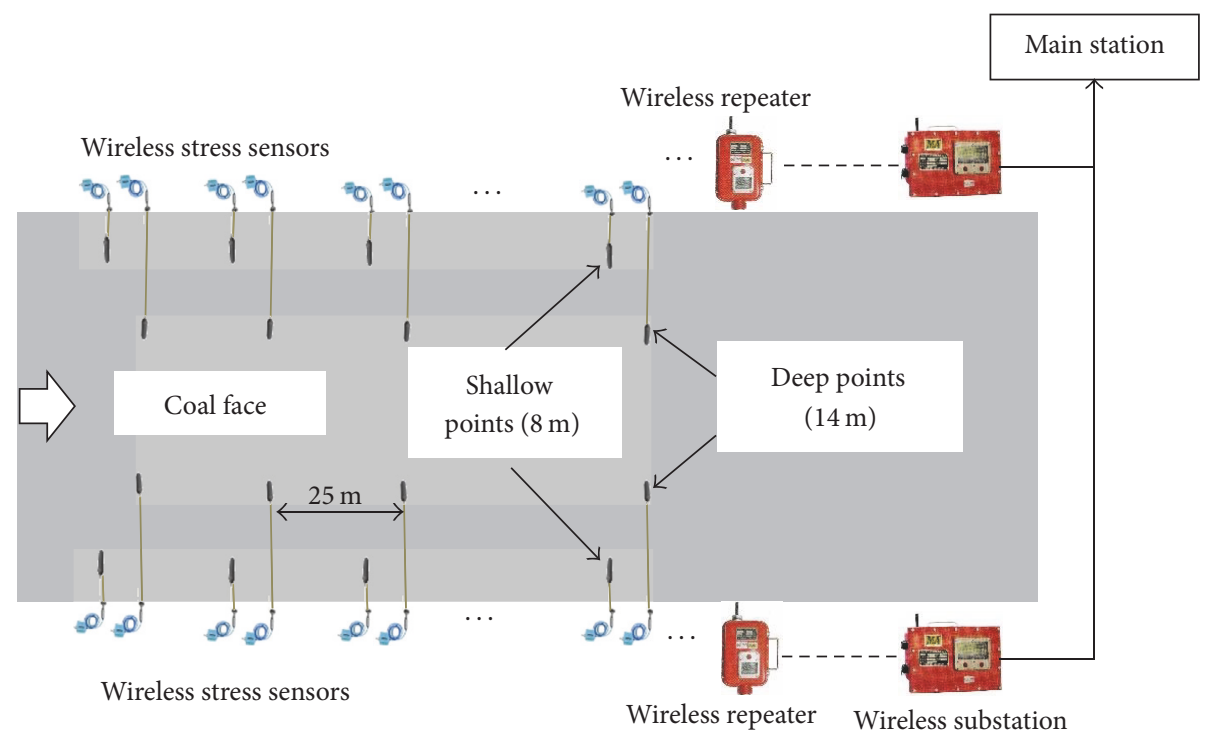

(a) KJ743 stress monitoring system

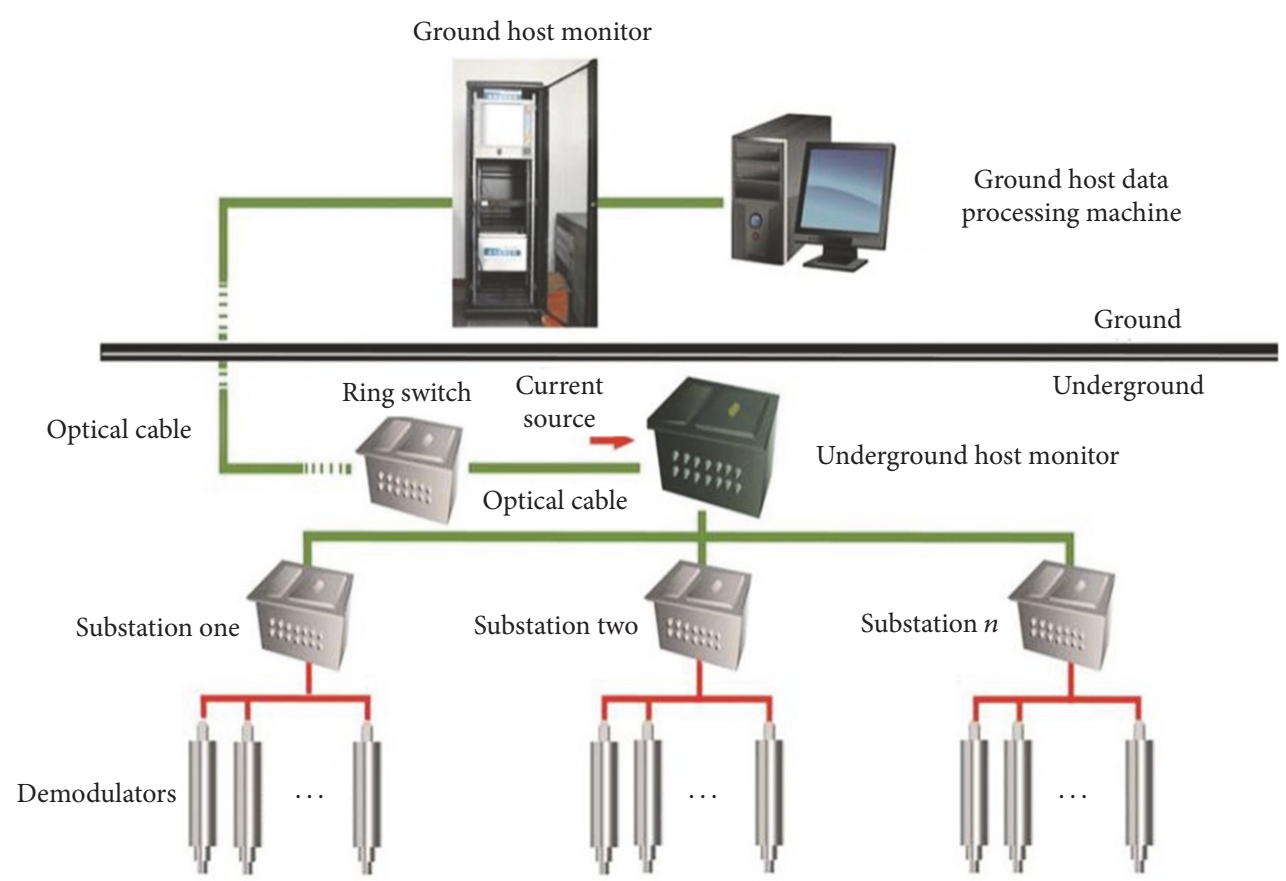

(b) KJ551 microseismic monitoring system

FIGURE 6: Monitoring systems and devices.

surface present failure characteristics of stick-slip. When the fault becomes active, the massive elastic energy accumulated in the peak district of stress will be released instantly, which leads to the occurrence of fault-slip rock burst.

(2) A mechanical model of stick-slip instability for faultslip rock burst was established here, and the failure characteristics of fault stick-slip instability were revealed. This study shows that before fault-slip rock burst takes place, the energy of microseismic events shows a characteristic repetitive signal that increases and then decreases, with the mining-induced stress in the coal rising rapidly. Therefore, multiparameter integrated prediction and early warning systems for faultslip rock burst can be realized by establishing a system that measures multiple parameters such as stress and energy.

(3) Based on the verification and monitoring in Suncun Coal Mine, the precursory information of rock burst matched well with the occurrence of fault-slip rock burst, and the multiparameter integrated prediction methods provided security for mining of subsequent working faces. 


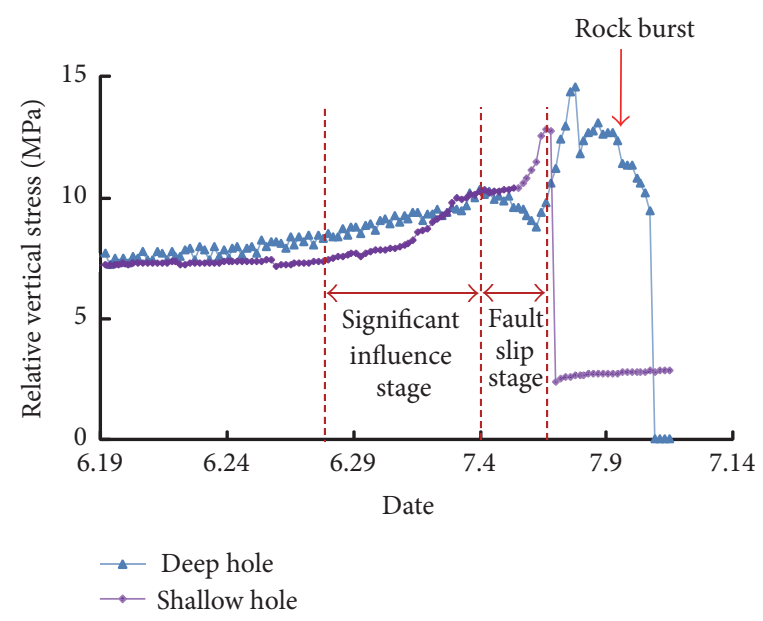

(a) Mining-induced stress

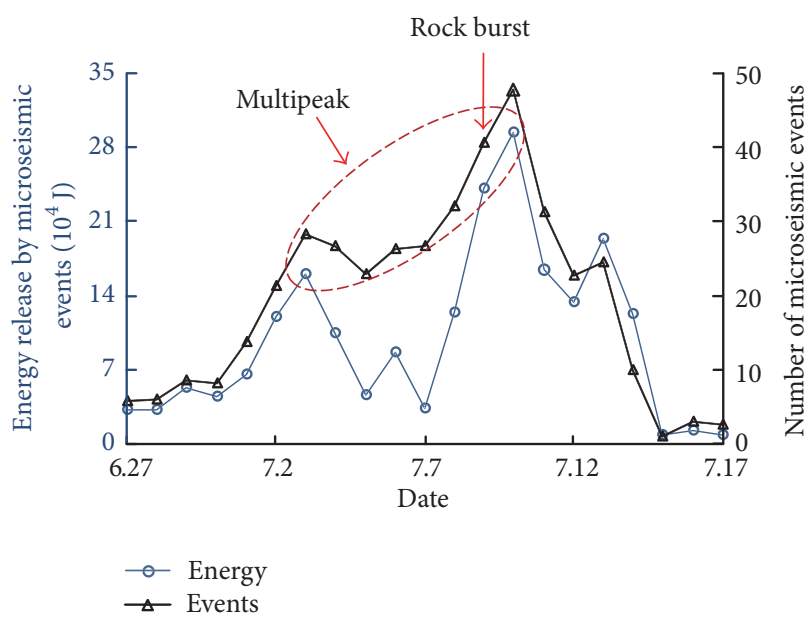

(b) Microseismic results

FIGURE 7: Monitoring results of fault-slip rock burst.

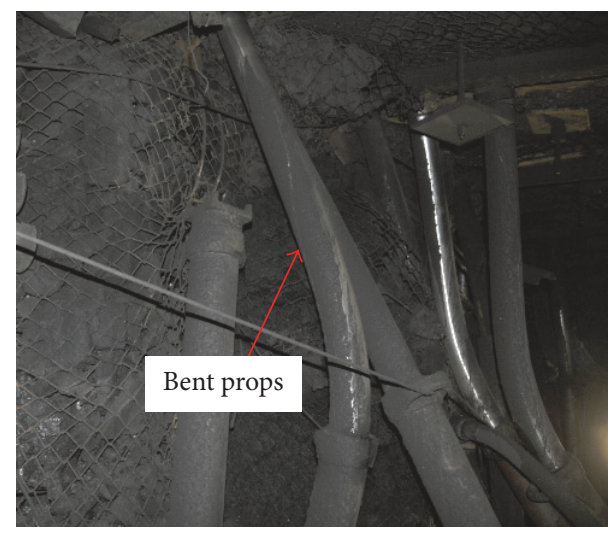

FIGURE 8: Field destruction as a result of rock burst.

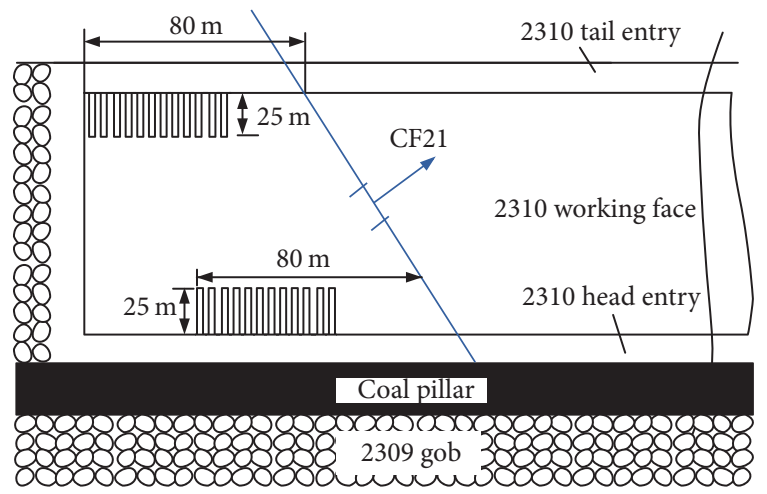

FIgURE 9: Arrangement of destressing boreholes on working face.

(4) Considering the geological conditions of Suncun Coal Mine, large-diameter borehole was adopted to perform pressure relief. The peak value of seismic energy of working

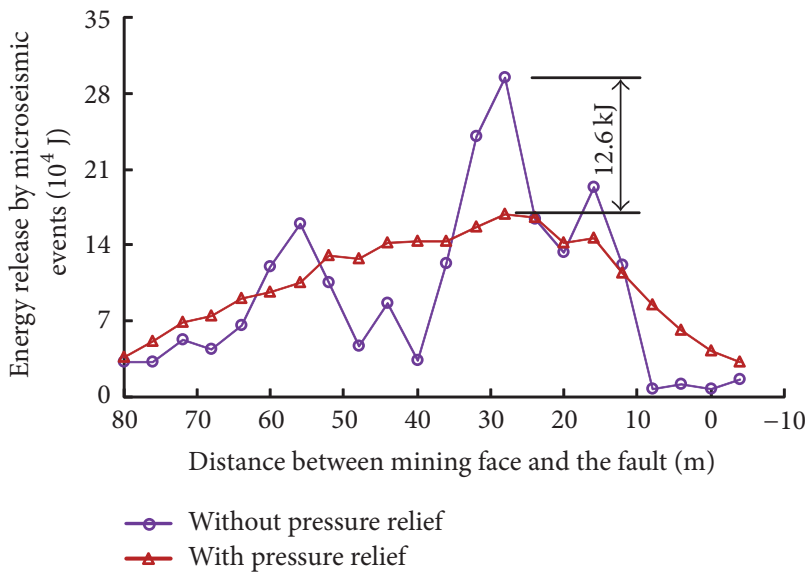

FIgure 10: Change in microseismic energy with and without pressure relief measures.

face 2310 (with pressure relief) only accounted for $57.1 \%$ of that of working face 2309 (without pressure relief), and the rock burst hazard of the working face was obviously relieved.

\section{Conflicts of Interest}

The authors declare that there are no conflicts of interests regarding the publication of this paper.

\section{Acknowledgments}

The research described in this paper was financially supported by China Postdoctoral Science Foundation Funded Project (no. 2016M592220), the State Key Research Development Program of China (no. 2016YFC0801403), National Natural Science Foundation of China (nos. 51574154 and 
51474137), Tai'shan Scholar Engineering Construction Fund of Shandong Province of China, and Qingdao Postdoctoral Applied Research Project (no. 2015198).

\section{References}

[1] A. Sainoki and H. S. Mitri, "Dynamic behaviour of mininginduced fault slip," International Journal of Rock Mechanics and Mining Sciences, vol. 66, no. 1, pp. 19-29, 2014.

[2] T. Zhao, W. Guo, Y. Tan, C. Lu, and C. Wang, "Case histories of rock bursts under complicated geological conditions," Bulletin of Engineering Geology and the Environment, pp. 1-17, 2017.

[3] T. J. Williams, C. J. Wideman, and D. F. Scott, "Case history of a slip-type rockburst," Pure and Applied Geophysics, vol. 139, no. 3-4, pp. 627-637, 1992.

[4] W. D. Ortlepp, "Observation of mining-induced faults in an intact rock mass at depth," International Journal of Rock Mechanics and Mining Sciences, vol. 37, no. 1-2, pp. 423-436, 2000.

[5] B. G. White and J. K. Whyatt, "Role of fault slip on mechanisms of rock burst damage, Lucky Friday Mine, Idaho, USA," in Proceedings of the 2nd Southern African Rock Engineering Symposium, Johannesburg, South Africa, September 1999.

[6] L. A. M. Castro, T. G. Carter, and N. Lightfoot, "Investigating factors influencing fault-slip in seismically active structures," in Proceedings of the 3rd Can-US Rock Mechanics Symposium, Toronto, Canada, 2009.

[7] Y. Tan, Y. Yin, S. Gu, and Z. Tian, "Multi-index monitoring and evaluation on rock burst in Yangcheng Mine," Shock and Vibration, vol. 2015, Article ID 624893, 5 pages, 2015.

[8] M. K. Abdul-Wahed, M. Al Heib, and G. Senfaute, "Mininginduced seismicity: Seismic measurement using multiplet approach and numerical modeling," International Journal of Coal Geology, vol. 66, no. 1-2, pp. 137-147, 2006.

[9] J.-A. Wang and H. D. Park, "Comprehensive prediction of rockburst based on analysis of strain energy in rocks," Tunnelling and Underground Space Technology, vol. 16, no. 1, pp. 49-57, 2001.

[10] Z. Wen, X. Wang, L. Chen, G. Lin, and H. Zhang, "Size effect on acoustic emission characteristics of coal-rock damage evolution," Advances in Materials Science and Engineering, vol. 2017, Article ID 3472485, 8 pages, 2017.

[11] Y. L. Tan, F. H. Yu, J. G. Ning, and T. B. Zhao, "Design and construction of entry retaining wall along a gob side under hard roof stratum," International Journal of Rock Mechanics and Mining Sciences, vol. 77, pp. 115-121, 2015.

[12] S. M. Spottiswoode, "Perspectives on seismic and rockburst research in the South African gold mining industry: 1983-1987," Pure and Applied Geophysics PAGEOPH, vol. 129, no. 3-4, pp. 673-680, 1989.

[13] Y.-S. Pan, L.-G. Wang, M.-T. Zhang, and B.-Y. Xue, "The theoretical and testing study of fault rockburst," Chinese Journal of Rock Mechanics and Engineering, vol. 17, no. 6, pp. 642-649, 1998.

[14] Z.-H. Li, L.-M. Dou, A.-Y. Cao, J. Fan, and Z.-L. Mu, "Mechanism of fault slip induced rockburst during mining," Journal of the China Coal Society, vol. 36, supplement 1, pp. 68-73, 2011.

[15] Q.-X. Qi, Y.-W. Shi, and T.-Q. Liu, "Mechanism of instability caused by viscous sliding in rock burst," Journal of China Coal Society, vol. 22, no. 2, pp. 144-148, 1997.

[16] T. Wang, Z.-H. Wang, Y.-D. Jiang, and W.-J. Wang, "Experimental study of stress distribution and evolution of surrounding rock under the influence of fault slip induced by mining,"
Journal of China University of Mining and Technology, vol. 43, no. 4, pp. 588-592, 2014.

[17] W. Gong, Y. Peng, H. Wang, M. He, L. Ribeiro e Sousa, and J. Wang, "Fracture angle analysis of rock burst faulting planes based on true-triaxial experiment," Rock Mechanics and Rock Engineering, vol. 48, no. 3, pp. 1017-1039, 2015.

[18] A. Sainoki and H. S. Mitri, "Dynamic modelling of fault slip induced by stress waves due to stope production blasts," Rock Mechanics and Rock Engineering, vol. 49, no. 1, pp. 165-181, 2016.

[19] A. Sainoki and H. S. Mitri, "Effect of fault-slip source mechanism on seismic source parameters," Arabian Journal of Geosciences, vol. 9, no. 1, pp. 1-12, 2016.

[20] A. Sainoki and H. S. Mitri, "Dynamic modelling of fault-slip with Barton's shear strength model," International Journal of Rock Mechanics and Mining Sciences, vol. 67, pp. 155-163, 2014.

[21] A. Sainoki and H. S. Mitri, "Effect of slip-weakening distance on selected seismic source parameters of mining-induced faultslip," International Journal of Rock Mechanics and Mining Sciences, vol. 73, pp. 115-122, 2015.

[22] Y. L. Tan, X. S. Liu, J. G. Ning, and Y. W. Lu, "In situ investigations on failure evolution of overlying strata induced by mining multiple coal seams," Geotechnical Testing Journal, vol. 40, no. 2, pp. 1-14, 2017.

[23] F.-X. Jiang, X.-H. Miao, C.-W. Wang, J.-H. Song, J.-M. Deng, and F. Meng, "Predicting research and practice of tectoniccontrolled coal burst by microseismic monitoring," Journal of the China Coal Society, vol. 35, no. 6, pp. 900-903, 2010.

[24] Z. Li, L. Dou, W. Cai et al., "Investigation and analysis of the rock burst mechanism induced within fault-pillars," International Journal of Rock Mechanics and Mining Sciences, vol. 70, no. 9, pp. 192-200, 2014.

[25] J.-G. Lü, Y.-D. Jiang, S.-G. Li, S.-D. Ren, W.-Z. Jiang, and Z.-C. Zhang, "Characteristics and mechanism research of coal bumps induced by faults based on extra thick and hard roof," Journal of the China Coal Society, vol. 39, no. 10, pp. 1961-1969, 2014.

[26] Y. Jiang, T. Wang, T. Chen, X. Bai, and S. Xie, "Features of coal bumps influenced by normal faults in coal mining with hard roof and hard coal," Chinese Journal of Rock Mechanics and Engineering, vol. 32, no. 2, pp. 3712-3718, 2013.

[27] H.-W. Zhang, F. Zhu, J. Han, B.-J. Huo, H. Rong, and G.-S. Tang, "Geological dynamic conditions and forecast technology for rock bursts," Journal of the China Coal Society, vol. 41, no. 3, pp. 545-551, 2016.

[28] Y.-D. Jiang, Y.-S. Pan, F.-X. Jiang, L.-M. Dou, and Y. Ju, "State of the art review on mechanism and prevention of coal bumps in China," Journal of China Coal Society, vol. 39, no. 2, pp. 205-213, 2014.

[29] X. S. Liu, J. Tan, Y. L. Tan, and S. C. Hu, "Pattern recognition of signals for the fault-slip type of rock burst in coal mines," Shock and Vibration, vol. 2015, Article ID 806969, 8 pages, 2015. 


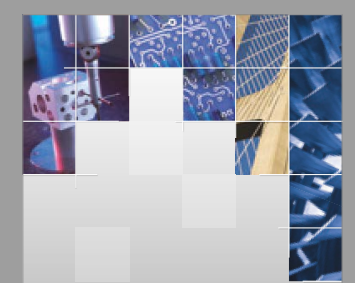

\section{Enfincering}
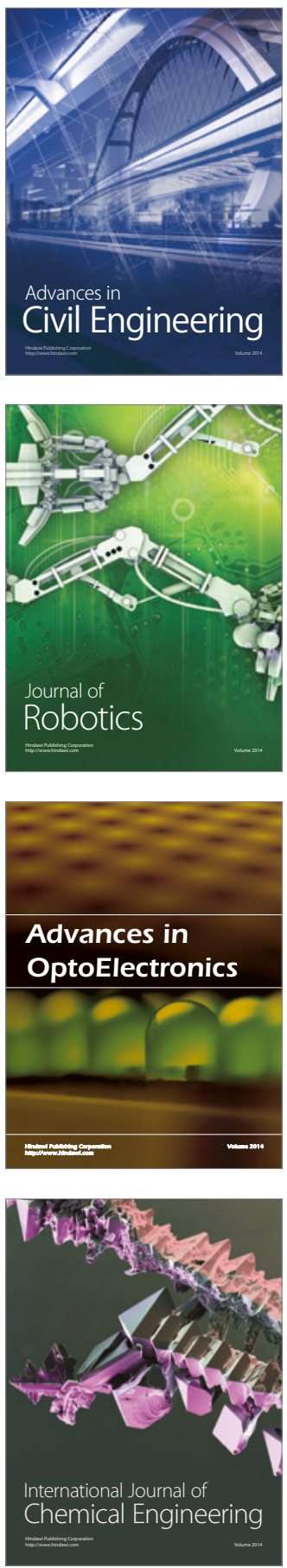

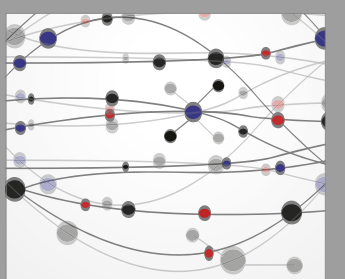

The Scientific World Journal

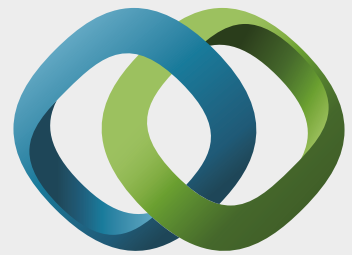

\section{Hindawi}

Submit your manuscripts at

https://www.hindawi.com
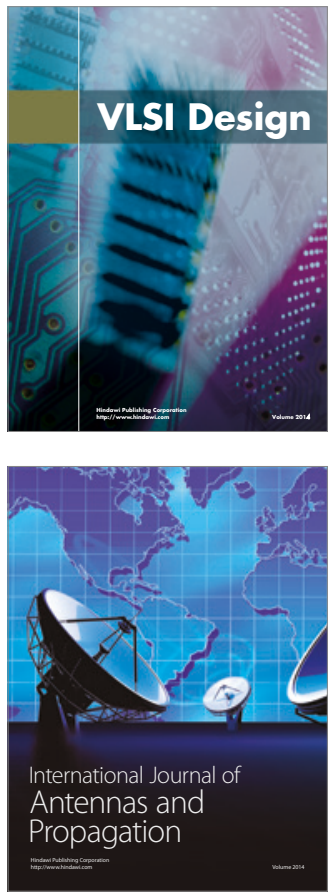

\section{Rotating}

Machinery
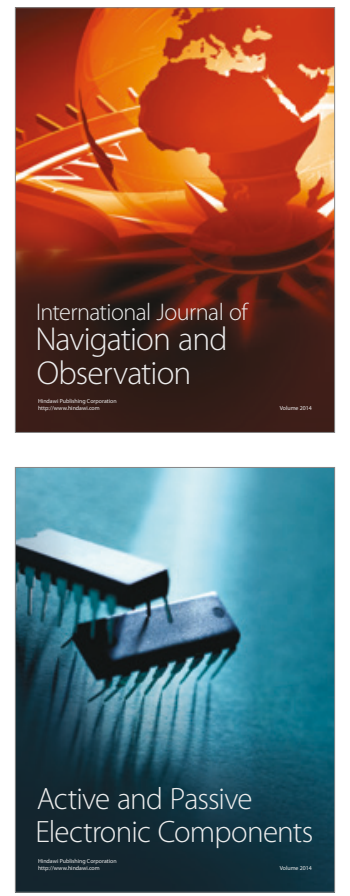
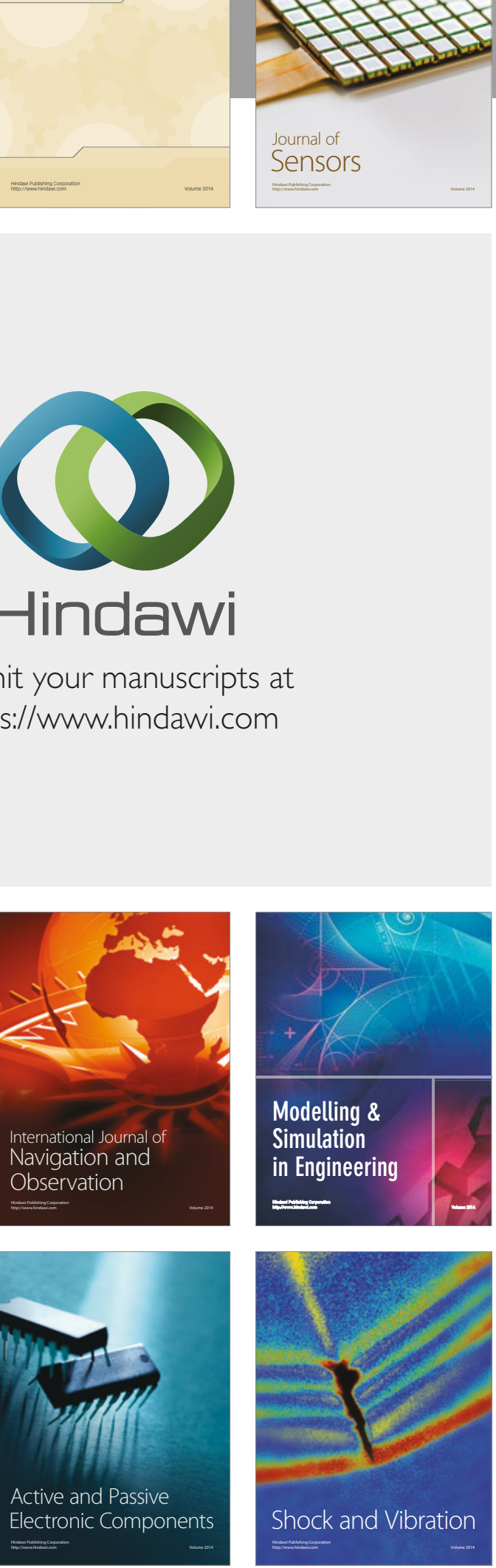
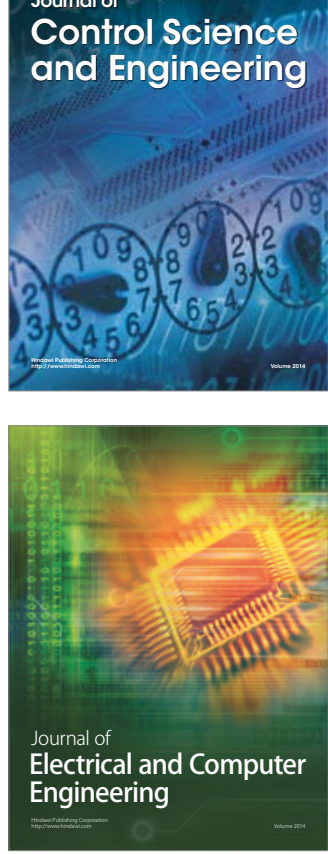

Distributed

Journal of

Control Science

and Engineering
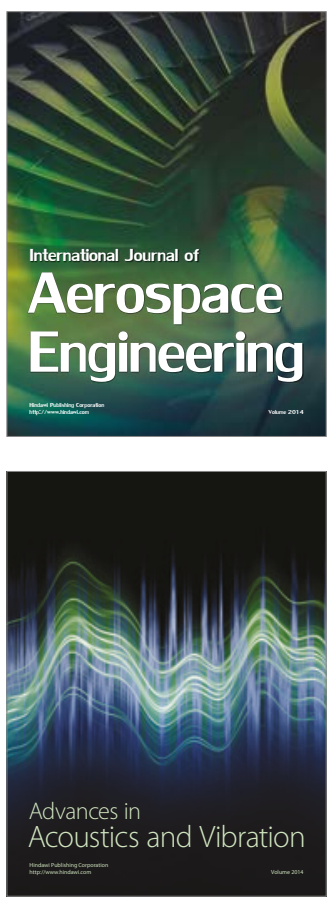

Sensor Networks 